\title{
Relative Age Effect and the Re-Selection of Danish Male Handball Players for National Teams
}

\author{
by \\ Christian M. Wrang ${ }^{1}$, Niels N. Rossing ${ }^{1}$, Rasmus M. Diernæs ${ }^{1}$, \\ Christoffer G. Hansen ${ }^{1}$, Claus Dalgaard-Hansen², Dan S. Karbing ${ }^{1}$
}

The relationship between the date of birth and expertise in various sports among both elite and youth level athletes is well established, and known as the relative age effect (RAE). However, new results in for example Canadian Hockey and British cricket and rugby have indicated a reversal of RAE among selected talents where the youngest athletes are more likely to remain selected than their older peers. As such, RAE may therefore depend on the age and the level of competition. The purpose of this study was therefore to analyse RAE from the youth to senior national level in a sample of successful Danish male national teams. The sample included 244 players from Danish under-19, under-21 and senior national levels. These players have been part of successful teams, winning 18 medals at 24 youth European and World championships and 8 medals during 12 years at the senior level. The results showed a significant RAE on both youth and national levels. However, RAE was less marked from the under-19 to under-21 and further to the senior national level. Results show that at the national youth level talent selection favours the relatively older players, of whom a larger proportion fails to be re-selected to the senior level compared to their younger peers. RAE appears to play a central and reversing role in the identification and re-selection in Danish male handball. The results also show that the presence of both a constant and constituent year structure affects $R A E$, even when introduced at late adolescence.

Key words: expertise, talent, development, re-selection.

\section{Introduction}

In several sports such as senior elite soccer (Helsen et al., 2012), youth basketball (Delorme and Raspaud, 2009), senior elite ice hockey (Baker and Logan, 2007), youth and senior rugby (Till et al., 2010) and youth handball (Schorer et al., 2013), the athletes' date of birth has been found to be a significant determinant for success. This is the so-called relative age effect (RAE) that refers to the difference of age between individuals in the same age group, which significantly affects the possibility of reaching the elite level (Ostapczuk and Musch, 2013). Relative age effect is a well-known phenomenon at both national youth (Helsen et al., 2005) and senior elite levels across nations and sports (Schorer et al., 2013). The effect is based on studies from recent decades, where researchers report that attaining elite level may be more difficult for relatively young sports participants (Cobley et al., 2009; Helsen et al., 2012; Musch and Grondin, 2001).

Schorer and colleagues (2013) have lately pointed out that the term relative age effect primarily is used on a 12-month annual age grouping, but also has been used to describe similar effects. Those authors specified that two structures of age were present in handball depending on whether the athletes played in national or international systems. The international handball federation (IHF) has

1 - Department of Health Science and Technology, Aalborg University, Aalborg, Denmark.

2 - National Coach for national youth teams, Danish Handball Federation, Brøndby, Denmark. 
structured international youth tournaments with fixed two-year age cohorts. This means that national youth players constantly are the relatively youngest or oldest on the youth national levels with up to two years of difference in the birth date. This is a grouping system that Schorer et al. (2013) have termed "constant year" (i.e. constant year effect). Participation in handball clubs is mostly organized with two-year age groupings that change every year. Thus providing a more dynamic structure seems relevant since the relative age of the participants changes from being in the oldest year to the youngest year throughout the development process. Medic et al. (2007) referred to this progression through the age band as an athlete's "constituent year", hence the constituent year effect. Players at international levels will therefore perform within two different structures with related effects. So far, few researchers have investigated RAE in handball (Aguilar et al., 2017). Consequently, the progression of players influenced by two different structures of age has lacked attention, and needs to be investigated in order to understand the development of players embedded in both structures.

The division of young athletes into age groups has been based on the assumption that it reduces maturational differences. However, studies have clearly indicated a great risk that coaches have confused maturation for talent, thereby leading to increased likelihood that relatively older youths were predominantly identified as being talented and selected for higher levels of competition (Ashworth and Heyndels, 2007; Schorer et al., 2013). Some evidence exists to suggest that this biased talent selection is a cause of RAE (Sherar et al., 2007), when considering the consequences of being selected (or not selected) for the subsequent level of development (Schorer et al., 2009). Therefore, research primarily has focused on the maturationselection hypothesis, which is based on the idea that athletes born shortly after the selection date benefit from their advanced physical and cognitive maturation.

The majority of previous studies have focused on RAE within a population at a given point in time with only few studies investigating RAE over time and its impact on the progression of talent selection and development. Recent studies in Canadian hockey (Gibbs et al., 2012), British rugby (McCarthy and Collins, 2014) and British cricket (McCarthy et al., 2015) have found that the likelihood of success for the youngest seems to be greater compared to that of older peers after being selected for a talent development programme. A recent study (Sæther, 2015) concluded that RAE seemed to be a major factor in the selection of youth national level soccer players in Norway. However, one limitation of this notable study is that the cohort of the study did not include the senior national level, preventing analysis of RAE in the selection to what can be considered the final endpoint of talent progression in soccer. Unfortunately, few studies include empirical evidence that links international participation of younger athletes from earlier to later stages of their athletic careers (Barreiros et al., 2014; Barreiros and Fonseca, 2012). Both of Barreiros and colleagues' studies concluded that selection of talent during youth was not a precondition for later success in sport, since a low fraction of players was re-selected from the youth to the senior national level. Furthermore they did not link RAE to the reselection of players.

The purpose of this study was to investigate the relative age effect and re-selection from the youth to the senior national level in Danish national handball. The specific objective was to investigate the distribution and reselection of players across national youth and senior levels, allowing investigation of the combined RAE when two talent development structures were interacting.

\section{Methods}

\section{Participants}

The sample of this study included Danish male handball players $\left(n_{t}=244\right)$ born from 1980 to 1991. We selected this specific talent programme as the under-19 (U19) and under-21 (U21) youth national levels had a successful record in international championships with 18 medals in 24 competitions, while the senior national level won 8 medals in 12 and recently won the Olympics in 2016. All players had been participating in at least one of the national levels: U19, U21 or senior national level and were compiled from the database of the Danish Handball Federation (DHF). These players had 
also belonged to Danish youth handball clubs that all operated within a constituent structure, and were therefore influenced by both constant- and constituent year effects. Furthermore records of participation in international tournaments such as European and World Championships as well as Olympic Games were compiled from the International and European Handball Federations' database (IHF and EHF). The records of the tournaments were from the 2003 World Championships up to and including the 2017 World Championships.

The database listed the players' name, date of birth and numbers of matches played at U19, U21 or senior levels. Selection of players to participate at national levels above their age is rare. Thus, the sample excluded players born after 1991, since they had a minimal possibility to debut at the senior national level. Overall, 201 players participated in U19, 166 in U21, and 75 at the senior national level with 30 players from the senior national level selected for an international senior tournament.

\section{Statistical Analysis}

Chi-squared tests were performed to determine if there was a RAE on U19, U21, senior levels and at international tournaments such as World and European Championships as well as the Olympic Games (significance set at $p<0.05$ ). Yet, U19, U21, senior and tournament levels represent not only one team, but all the players who participated at the exact levels during the investigated year span. The U19 level therefore refers to all the players, born from 1980 to 1991, who participated in the U19 team. The same applies for the U21, senior and tournament levels.

To represent the constant two-year agespan of the national levels, the relative age was calculated from three-month groupings giving a total of eight quarters, four birth quarters for each year with the cutoff date in handball at the $1^{\text {st }}$ of January. The chi-squared tests were performed by comparing frequencies of players from the eight birth year quarters for each level with the expected frequencies. As in previous studies on RAE, it was assumed that birth quarters were equally distributed at these levels, i.e. giving expected frequencies for the eight birth quarters of $12.5 \%$. At the tournament level the eight birth quarters were combined into four half-year groups, since the expected values of chi-squared analysis otherwise would be below five. The expected equal distribution has been questioned by Delorme and colleagues (Delorme et al., 2009; Delorme and Raspaud, 2009), yet since the main focus of this study was to investigate the selection and re-selection of players we chose to use an expected equal distribution as well as a normalized distribution based on previous selections.

The number of players in each sample decreased as the competitive level increased, with the U19 sample having more than 6 times the number of players compared to the international senior tournament sample. Considering that the chi-squared test is considered sensitive to sample size (Delorme and Champely, 2013), we performed a further chi-squared test for each sample, where the sample size was normalized by using the observed fraction of players in each birth quarter to calculate how many would be observed if these fractions were considered in a sample of 201 players, i.e. normalizing the analysis to the number of players in the U19 sample.

\section{Results}

\section{RAE from the national youth to the senior level and international tournaments}

Figure 1 shows the distribution of birth quarters among players in U19, U21, senior and senior tournament teams for players born between 1980 and 1991. The first four birth quarters include the majority of players in U19 and U21, while players are more equally distributed at the senior and tournament level. Specifically, the proportion of players from the first three birth quarters decreases from U19 to senior levels, while the proportions of players from the fifth, sixth and eighth birth quarter increase. This is supported by the chi-squared test results summarized in Table 1 showing a significant difference between player distribution and the expected equal distribution of players at $\mathrm{U} 19(p<0.001)$ and $\mathrm{U} 21(p<0.001)$ national levels, and with no significant difference for the senior national $(p=0.363)$ nor the tournament level $(p=$ 0.764). However, despite different dispersion between birth quarters in the samples, the normalized chi-squared analysis showed significant RAE in all samples $(p<0.05)$ if the proportions of players in each birth quarter had 
been observed in a sample of the same size as the U19 sample.

\section{Relative age and the re-selection of players}

While Figure 1 shows the distribution of players at each level, Figure 2 shows the players being re-selected for teams at higher competitive national levels. Figure 2 shows that the players with the greatest possibility for re-selection from U19 to U21 and from U21 to senior levels were players born in the eighth birth quarter. On the other hand, the proportion of players who failed to be re-selected from U19 to U21 and from U21 to senior levels was highest for players born in the first four birth quarters. This is also supported by the chi squared test results showing a significant difference between the successfully re-selected players' distribution and the expected equal distribution of re-selected players at U19-U21 ( $p<$ $0.001)$ and U21-senior levels $(p<0.001)$.

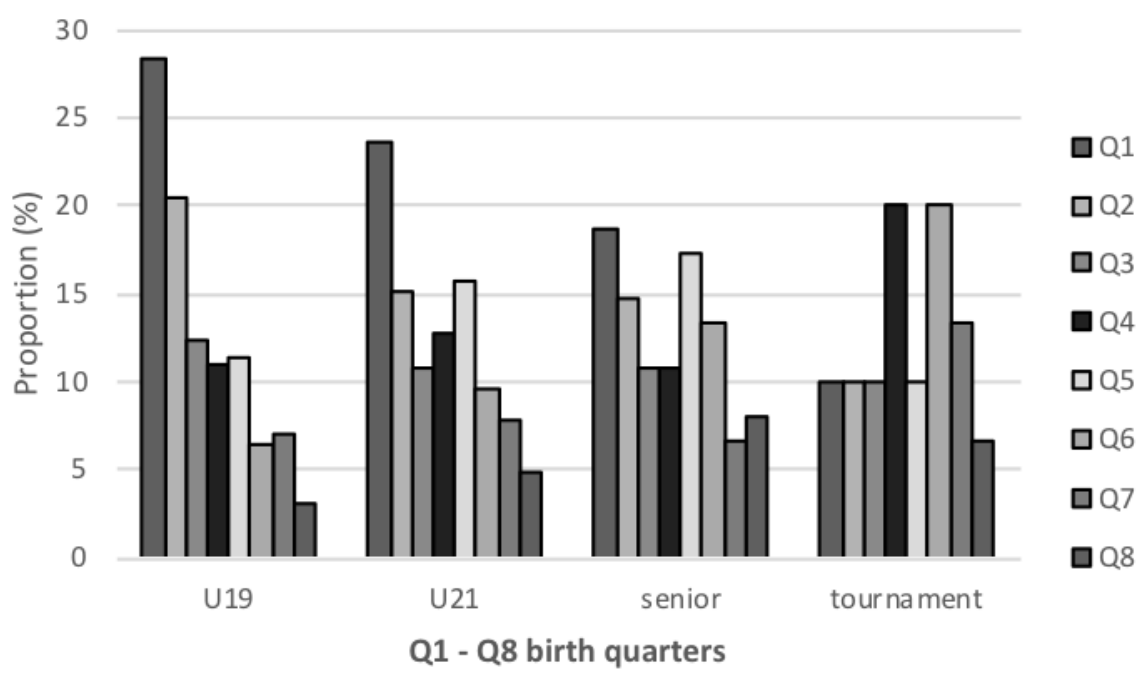

Figure 1

The distribution of players across each birth quarter in percentage, at U19, U21, senior national levels and tournament participation, respectively.

Q1 - Q8 are organized from left to right.

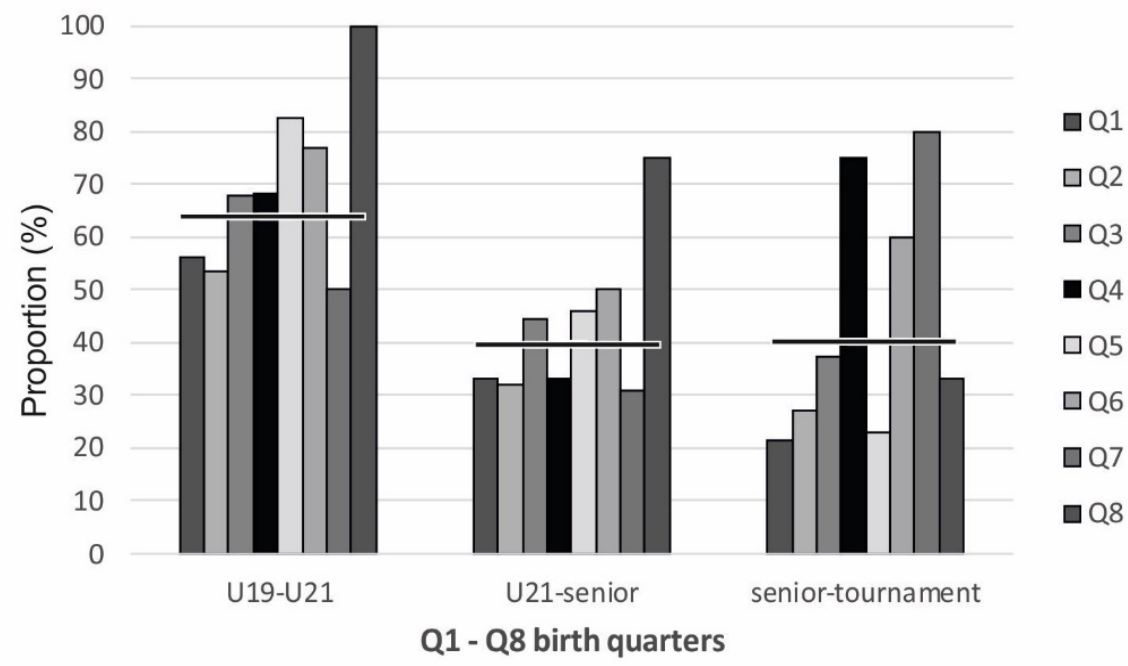

Figure 2

The distribution of players re-selected from U19 to U21, U21 to the senior national level and the senior national level to tournament participation across each birth quarter. $Q 1-Q 8$ are organized from left to right. 


\begin{tabular}{|c|c|c|c|c|c|c|c|c|c|c|c|}
\hline \multicolumn{12}{|c|}{$\begin{array}{l}\text { Table } \mathbf{1} \\
\text { Proportion and number of players in each birth quarter for the four different competitive } \\
\text { levels and p-values for chi-squared and normalized chi-squared analysis. }\end{array}$} \\
\hline Team & & Q1 & Q2 & Q3 & $\mathrm{Q} 4$ & Q5 & Q6 & Q7 & $\mathrm{Q} 8$ & $\mathrm{X}^{2} \mathrm{P}$ & $\begin{array}{l}\text { Norm. } X^{2} \\
\mathrm{P}\end{array}$ \\
\hline U19 & n (\%) & $57(28.4)$ & $41(20.4)$ & $25(12.4)$ & $22(10.9)$ & $23(11.4)$ & $13(6.5)$ & $14(7.0)$ & $6(3.0)$ & $<0.001$ & $<0.001$ \\
\hline U21 & $\mathrm{n}(\%)$ & $39(23.5)$ & $25(15.1)$ & $18(10.8)$ & $21(12.7)$ & $25(15.1)$ & $17(10.2)$ & $13(7.8)$ & $8(4.8)$ & $<0.001$ & $<0.001$ \\
\hline Senior & $\mathrm{n}(\%)$ & $14(18.7)$ & $11(14.7)$ & $8(10.7)$ & $8(10.7)$ & $13(17.3)$ & $10(13.3)$ & $5(6.7)$ & $6(8.0)$ & 0.363 & 0.005 \\
\hline Tournament & $\mathrm{n}(\%)$ & $3(10.0)$ & $3(10.0)$ & $3(10.0)$ & $6(20.0)$ & $3(10.0)$ & $6(20.0)$ & $4(13.3)$ & $2(6.7)$ & 0.764 & $<0.001$ \\
\hline
\end{tabular}

Strikingly, the proportion of players successfully re-selected from the senior level to tournament participation is lowest at the first and the fifth birth quarter and highest at the fourth and the seventh. The chi-squared test's results shows that the distribution of successfully reselected players from the senior level to tournament participation is not significantly skewed $(p=0.753)$.

\section{Discussion}

There are two main findings from this study to be discussed. We found a significant RAE at the youth male handball national levels, but not at the senior national or tournament level, although when normalised to the largest sample size a significant RAE was present in all samples, yet with greater skew between birth quarters in the lowest competitive levels. Our results also show that relatively younger players in the constant two-year age cohort at the national youth level had better chances for re-selection to the senior national level compared to their older peers.

\section{The distribution of players is skewed at national levels}

The results show a relative age effect at national youth levels as expected. Based on the normalized chi-squared tests at senior and tournament levels, the distribution remains skewed at all four levels, although less marked with increasing age. The difference between the highest and the lowest percentage per quarter at each level decreases from $25 \%$ at U19 to $19 \%$ at $\mathrm{U} 20,12 \%$ at senior and $13 \%$ at tournament levels. Recent studies have indicated that RAE may already exist in the registered youth player populations the national youth level players are selected from. Our results indicate that this RAE is continued or further exaggerated at the national youth level, likely making the player population that senior national team coaches select from also skewed. For instance, studies in French basketball (Delorme and Raspaud, 2009) and Canadian ice hockey (Lemez et al., 2014) found that the registered youth player populations were skewed towards relatively older players, and that dropout seemed to occur more often among younger 
players. Already in the early sport participation, the age grouping of young athletes may cause a skewed youth player population (Delorme and Champely, 2013). If this is the case, identification of talented players by national youth coaches may be proportionally appropriate. Another explanation may be that the majority of older players firstly selected to the talent program benefit from the resources and environment at the national teams, from where they get a better chance of further re-selection. It has previously been suggested that RAE in youth may be due to enhanced physical differences (Malina et al., 2005) or increased fitness levels (Carling et al., 2009) in favor of the oldest players. However, Schorer (2009) found no physical or skill differences between relative young or old youth German handball players, which suggests alternative hypotheses.

However, it remains to be determined to what degree these possible causes contribute to RAE and whether this occurs consistently across sports and countries.

RAE favouring younger players in re-selection to the senior level

The results demonstrate that the youngest players more often succeeded in reaching the elite senior level compared to their older peers. As such, many of the older players at youth national levels were de-selected for the senior national level, while most of their younger peers succeeded in reaching the elite national level. McCarthy and Collins (2014) observed a "reversal" of RAE benefits as relatively younger British Rugby players were overrepresented at the senior elite level. Although the current study's data shows decreasing skewness, it does not show a complete reversal. The less pronounced reversal observed in the present study in comparison to the one found in the study of McCarthy and Collins (2014), may be due to players being influenced by both a constant and constituent year effect throughout their youth career. Studies in German handball (Schorer, 2009) and French soccer (Carling et al., 2009) have also shown that relatively younger players may be discriminated during youth, but succeed better in the transition from the youth elite to the senior elite level than their older peers. This is in line with a previous study in Canadian ice-hockey by Gibbs and colleagues (2012), who found that relatively younger players in their senior career had higher probability than their peers to enter All-star teams and Olympic team rosters through the underdog effect. The different progression of younger and older players in Danish male handball through youth to senior national teams and tournament rosters may reflect different development paths. It is possible that the younger players face more life stressors than their older peers, and learn resilience as well as mental toughness on their way to the senior elite, which Collins and MacNamara (2012) suggest being crucial for athlete's senior performance. As Mikkel Hansen (voted "MVP" in the World Championship 2013) reports: "Because I was younger and smaller than those I practiced with and played against, I was forced to work on and improve all the details of the game in order to succeed. It has undoubtedly, unconsciously, contributed to a good learning strategy. I also learned to handle adversity and defeat in contrast to taller players who experienced early success" (translated from Danish, Rossing et al., 2015).

The annual age grouping of players is probably based on creating a fair environment and competition while also respecting other social contexts such as age groupings in school, other sports, etc. However, grouping players based on their age has certain disadvantages as shown in this study. The relatively youngest are limited at youth level selection, while the relatively oldest are limited at later selection. Thus creating a talent system, which operates with two levels of reduction of its own scope, since firstly potential talents are ignored at the entry level to the national youth levels and then the oldest players at later competitive levels are predominantly deselected, seems of utmost importance.

The results also suggest that a shift of effects occur. At the U19 national level, the distribution of players across the constant twoyear age band creates a constant year effect. When reselecting from U19 to U21 and further to the senior national level, the proportion of players born in the second constant year increases. Furthermore, the senior national level predominantly consists of players born in the two first birth quarters from each year. As the youth league is organized with a two year constituent structure, the relatively oldest players from the youngest constant year, that is players from the 
fifth birth quarter, experience being oldest every other year at the club level. Some of the benefits they experience as the relatively older player every other year, may assist them in reaching the senior national level. One possible explanation is that players from the fifth and sixth quarter every second year in the youth league experience being the relatively oldest, which possibly gives them more attention, playing time and practice at a higher playing level. Thus, the possibility of attaining the senior national level shifts from being influenced primarily by constant to constituent year effect.

\section{Applied perspective}

Since Helsen (2012) in a review proclaimed that 10 years of research in RAE did not seem to have influenced the relative age effect in soccer, practical perspectives on how to solve this issue seem warranted. Dalgaard-Hansen, who is a coauthor of works discussing RAE and operating as a Talent Development Manager in Danish Handball, for the players in the sample of this study, considers three things that every talent developer should be aware of in order to potentially limit RAE.

First of all, it is important for coaches to acknowledge the issue of RAE during daily activities such as training, matches, and when assessing the players' potential. The relative age is a crucial part of the whole picture. Based on a Mann and van Ginnekens (2016) study, players' relative age can be made visible by relating their shirt number to the player's birthdate. Alternatively, let the players wear shirt or wristbands in different colours according to their birth quarter in competitions and recruitment camps.

Secondly, in order to ensure attention to the players born in the youngest constant year at the national youth level, the national federations can divide the national youth teams into age groups with a maximal age difference of 12 months. Such actions have lately been introduced within the Danish Handball Federation (DHF), and thereby created better opportunities for players from the youngest year to receive attention, thus giving the national coaches and management a broader knowledge of the players from each constant year. It is well established that RAE occurs in 12 month groupings, suggesting that a 6 month grouping may be preferred if resources such as coaches, players, practice- and playing time are present.

Thirdly, acknowledgement to the players from coaches can be shown in other ways than selection to a talent program. Praising the players' effort and development during a conversation at the sports facility, a phone call or in an e-mail can also mean a lot for a young player. As a talent developer and practitioner, Dalgaard-Hansen finds it important to invest time and energy in both the selected and deselected players, and thereby create a bigger talent pool.

Dalgaard-Hansen believes that these actions potentially may limit RAE, but such an approach needs to be met with caution and investigated empirically in the future.

\section{Limitations}

The time span of sample data may have introduced noise to the analysis as replacement of national coaches and national senior matches of varied performance likely have had some impact on the identification and selection of talented players and hence RAE during the sample period. For instance, new coaches may have had different philosophies in terms of talent identification and development. Thus, the results presented here can only be considered as overall effects encompassing such changes.

\section{Conclusion}

The results show a significant relative age effect on the youth national levels of Danish handball with favoured players predominantly being the oldest in a two-year age band, but not at the senior national level. Furthermore, the advantage of being relatively older when entering the talent program reverses from the youth to the senior national level, with the relatively younger players being more likely to be re-selected. Thus, the relative age effect appears to play a central and reversing role in the identification and development of expertise in Danish male handball. The results also show that the presence of both a constant and constituent year structure affects RAE, even when introduced at late adolescence. 


\section{References}

Aguilar ÓG, García MS, Romero JJF. Constituent year effect in international handball at high level. J Hum Sport Exe, 2017; 12(2): 316-324

Ashworth J, Heyndels B. Selection Bias and Peer Effects in Team Sports The Effect of Age Grouping on Earnings of German Soccer Players. J Sports Econ, 2007; 8(4): 355-377

Baker J, Logan AJ. Developmental contexts and sporting success: birth date and birthplace effects in national hockey league draftees 2000-2005. Brit J Sport Med, 2007; 41(8): 515-517

Barreiros A, Côté J, Fonseca AM. From early to adult sport success: Analysing athletes' progression in national squads. Eur J Sport Sci, 2014; 14(sup1): 178-182

Barreiros AN, Fonseca AM. A Retrospective Analysis of Portuguese Elite Athletes' Involvement in International Competitions. Int J Sports Sci Coach, 2012; 7(3): 593-600

Carling C, Le Gall F, Reilly T, Williams AM. Do anthropometric and fitness characteristics vary according to birth date distribution in elite youth academy soccer players? Scand J Med Sci Spor, 2009; 19(1): 3-9

Cobley S, Baker J, Wattie N, Mckenna J. Annual Age-grouping and Athlete Develop- ment. A Metasanalytical Review of Relative Age Effects in Sport. Sports Med, 2009; 39(39): 235-256

Collins D, MacNamara Á. The Rocky Road to the Top. Why Talent Needs Trauma. Sports Med, 2012; 42(11): 907-914

Delorme N, Boiché J, Raspaud M. The relative age effect in elite sport: the French case. Res Q Exercise Sport, 2009; 80(2): 336-344

Delorme N, Champely S. Relative Age Effect and chi-squared statistics. Int Rev Sociol Sport, 2013; 50(6): 740746

Delorme N, Raspaud M. The Relative Age Effect in young French basketball players: a study on the whole population. Scand J Med Sci Spor, 2009; 2(19): 235-242

Gibbs BG, Jarvis JA, Dufur MJ. The rise of the underdog? The relative age effect reversal among Canadianborn NHL hockey players: A reply to Nolan and Howell. Int Rev Sociol Sport, 2012; 47: 644-649

Helsen WF, Baker J, Michiels S, Schorer J, Van Winckel J, Williams AM. The relative age effect in European professional soccer: Did ten years of research make any difference? J Sport Sci, 2012; 30(15): 1665-1671

Helsen WF, Van Winckel J, Williams AM. The relative age effect in youth soccer across Europe. J Sport Sci, 2005; 23(6): 629-636

Lemez S, Baker J, Horton S, Wattie N, Weir P. Examining the relationship between relative age, competition level, and dropout rates in male youth ice-hockey players. Scand J Med Sci Spor, 2014; 24(6): 935-942

Malina RM, Cumming SP, Morano PJ, Barron M, Miller SJ. Maturity Status of Youth Football Players: A Noninvasive Estimate. Med Sci Spor Exer, 2005; 37(20): 1044-1052

Mann DL, van Ginneken PJMA. Age-ordered shirt numbering reduces the selection bias associated with the relative age effect. J Sport Sci, 2016; 414(September): 1-7

McCarthy N, Collins D. Initial identification \&amp; selection bias versus the eventual confirmation of talent: evidence for the benefits of a rocky road? J Sport Sci, 2014; 32(17): 1604-1610

McCarthy N, Collins D, Court D. Start hard, finish better: further evidence for the reversal of the RAE advantage. J Sport Sci, 2015; 414(May): 1-5

Medic N, Starkes JL, Young BW. Examining relative age effects on performance achievement and participation rates in Masters athletes. J Sport Sci, 2007; 25(12): 1377-84

Musch J, Grondin S. Unequal competition as an impediment to personal development: A review of the relative age effect in sport. Dev Rev, 2001; 21: 147-167

Ostapczuk M, Musch J. The influence of relative age on the composition of professional soccer squads. Eur J Sport Sci, 2013; 13(3): 249-255

Rossing NN, Ryom K, Henriksen K. Talentudvikling $i$ sport. DIFO og Aalborg Universitetsforlag; 2015

Schorer J, Baker J, Büsch D, Wilhelm A, Pabst J. Relative age, talent identification and youth skill development: Do relatively younger athletes have superior technical skills? Talent Dev Excell, 2009; 1(1): 45-56

Schorer J, Wattie N, Baker JR. A new dimension to relative age effects: constant year effects in German youth handball. PloS One, 2013; 8(4): e60336 
Sherar LB, Baxter-Jones ADG, Faulkner RA, Russell KW. Do physical maturity and birth date predict talent in male youth ice hockey players? J Sport Sci, 2007; 25(8): 879-886

Sæther SA. Selecting players for youth national teams - A question of birth month and reselection? Sci Sports, 2015; 30(6): 314-320

Till K, Cobley S, Wattie N, O'Hara J, Cooke C, Chapman C. The prevalence, influential factors and mechanisms of relative age effects in UK Rugby League. Scand J Med Sci Spor, 2010; 20(2): 320-329

\section{Corresponding author:}

\section{Niels Nygaard Rossing}

Department of Health Science and Technology, Aalborg University, Aalborg, Fredrik Bajers vej 7 E2, 9220 Aalborg, Denmark.

Tel: + 45 99407603,

E-mail: nnr@hst.aau.dk 